$\mathrm{V}$ Von Dirk Hohnsträter erkehrte Welt: Während grüne Politiker baldiges Wirtschaftswachstum herbeisehnen, verkündet die Werbekampagne eines Medienmarktes, Geiz sei "geil". Sollte die Konjunkturkrise etwa die Konsumkritik beflügeln? Wendet sich der Slogan an geläuterte Verbraucher, die während der Wirtschaftsflaute entdecken, wie anziehend Askese ist? Der Eindruck täuscht. Es handelt sich vielmehr um eine Durchhalteparole, die auch bei knapper Kasse zum Geldausgeben animieren will. Niedrige Preise sollen leere Taschen, Teurogefühle und Terrorängste vergessen machen. Ist der Dispo auch überzogen und die Zukunft ungewiss, für ein wenig künftigen Elektronikschrott wird es schon noch reichen.

"Ich bin doch nicht blöd", wirbt eine weitere Einzelhandelskette und ermuntert Schnäppchenjäger, sich in schwierigen Zeiten die Kauflaune nicht verderben zu lassen. "Leute, leert die Regale!", rufen Verantwortliche den von Zukunftsängsten eingeschüchterten Verbrauchern zu. Auf einmal erscheint Billigkonsum als erste Bürgerpflicht, und mancher Mercedesfahrer zieht plötzlich das Schlangestehen bei Aldi dem Schwatz im Bioladen vor.

Aber wie smart sind shopper, die diese Art der Sparsamkeit sexy finden? Natürlich spricht nichts dagegen, Preise zu vergleichen und sich nicht über den Tisch ziehen zu lassen. Und niemand wird dagegen argumentieren, das Klopapier beim Discounter zu erwerben, damit genügend Geld für vernünftige Schuhe zurückbleibt. Problematisch ist hingegen, wenn Tiefpreise zum entscheidenden oder gar einzigen Kaufkriterium werden. Genau das legen die zitierten Kampagnen nämlich nahe. Bei ständigem Tiefpreis-Shopping geraten jedoch sozial-ökologische Kosten aus dem Blick und Konsumgewohnheiten verfestigen sich, deren nachteilige Folgen immer deutlicher zutage treten.

Trotz Wirtschaftskrise gilt unverändert, dass sich der Lebensstandard der westlichen Welt nicht globalisieren lässt, ohne das Ökosystem Erde zum Erliegen zu bringen. Verallgemeinerte man das fatale Vorbild der Industrieländer, hätte auch unser Wohlstand alsbald ein Ende. Zudem verringert heutiger Ressourcenverbrauch die Gestaltungsmöglichkeiten künftiger Generationen. Als Erben verarmter Verschwender werden sie sich genötigt sehen Wachstumszwängen nachzugeben, damit genug Geld in in den öffentlichen Kassen ist, um wenigstens die Schul-
Konsumverzicht und Nachhaltigkeit

\section{Krise als Chance?}

Kritik an der Konsumgesellschaft gehört zu den klassischen Themen ökologischen Denkens. Zügelloser Verbrauch nehme zu wenig Rücksicht auf die Umwelt. In Zeiten konjunktureller Schwäche üben immer mehr Menschen Kaufzurückhaltung. Erzwingen nun knappe Kassen, was über einen Wertewandel nicht erreichbar ist? Die aktuelle Entwicklung lässt eher Gegenteiliges befürchten.

den ihrer Vorfahren abzubezahlen - Innovationsspielräume blieben dabei kaum. Das alles ist hinlänglich bekannt, aber gerade während konjunkturschwacher Zeiten sinkt die Bereitschaft, sozial-ökologische Kosten zu berücksichtigen. Ehrliche Preise? Ich bin doch nicht blöd!

\section{- Aus der Not eine Tugend machen?}

Aus der ökonomischen Not eine ökologische Tugend zu machen, das scheint zumindest im Breitenbewusstsein weit weniger wahrscheinlich als ein trotziges Jetzt-erst-recht. Geiz ist geil, denn er ermöglicht krisenfestes Weiterkonsumieren. Interessanterweise tritt Überdruss an Überfluss und Wegwerfkultur gerade dann auf, wenn der Laden läuft. Vermutlich muss der Konsumkritiker den Konjunkturaufschwung innig herbeiwünschen, damit die Menschen wieder aus der Freiheit umfassender Wahlmöglichkeit heraus Nein zum Billigkonsum sagen können, anstatt von der Krise zu ihm gezwungen zu werden. Vielleicht lässt erst eine boomende Wirtschaft die Suche nach Alternativen zu und am Ende sogar Abstinenz attraktiv erscheinen.

Dabei sind es keineswegs nur abstrakte Universalisierungsargumente, die gegen die Hochkonjunktur der Niedrigpreise sprechen. Je weiter man sich einmal probehalber von den Selbstverständlichkeiten der Schnäppchenjagd entfernt, desto irrer kommt sie einem bisweilen vor. Ist es nicht seltsam, dass natürliche, gesunde und schmackhafte Nahrung in speziellen Geschäften verkauft wird, während der gemeine
Lebensmittelhandel jede Menge Produkte vertreibt, die zum günstigen Preis noch allerlei fragwürdige Zusatzstoffe gratis enthalten? Und was hält wohl eine unterbezahlte Näherin in einem armen Land von verwöhnten Verbrauchern, die ihre alten Jeans wegwerfen, damit sie sich beim Kauf einer künstlich auf alt getrimmten neuen einen kurzfristigen Kick verschaffen können? Von einem Discount des Denkens ist man versucht zu sprechen, wenn ausgerechnet Automobile und Fernreisen als authentisches Naturerlebnis angepriesen werden, obgleich sie genau das zerstören, was die Werbung mit ihnen assoziiert.

Aber es ist wenig aussichtsreich, sich über Wohlstandsbürger im Wühltischgedrängel zu erregen, zumal der Kritiker den Reizen raffinierter Reklame nicht selten selbst erliegt. Wichtiger wäre es, von der Wirksamkeit der Werbung zu lernen, die Lustseite souveränen Linksliegenlassens heraus zu stellen und den Gewinn an Lebensqualität, der mit alternativem Verbraucherverhalten einhergehen kann, zu betonen.

Für den einen oder anderen mag die Wirtschaftskrise Anlass sein, immer neue Bedürfnisse, Annehmlichkeiten und Ansprüche in Frage zu stellen. Damit beim nächsten Aufschwung nicht wieder die alte Maßlosigkeit zurückkehrt, sollten die Vorzüge von Verzicht und qualitätsgeleitetem Verbrauch akzentuiert werden. Wäre es nicht ungemein entspannend, an die Stelle stressiger Pfennigfuchserei ein ruhiges Wochenende zu setzen und erleichtert aufzuatmen? Könnten zunehmend einflusslose Bürger bewusste Kaufentscheidungen nicht als neuartige Partizipationschance ansehen? Welcher Genuss läge darin, gut beraten zu werden und sich an langlebigen, reparaturfreundlichen Gütern zu erfreuen ... Damit ginge übrigens Distinktionsbedürfnisse und den Hedonismus der Menschen nicht leugnend - ein qualitativ anderes Verständnis von Status und Luxus einher: weniger, aber besser. Gut ist geil. Sie sind doch nicht blöd, oder?

\section{Der Autor}

Dirk Hohnsträter ist Kulturwissenschaftler und promoviert über ästhetische Aspekte ökologischer Probleme.

Kontakt: Dirk Hohnsträter, Christburger Straße 5 , 10405 Berlin. E-Mail: Dirk.Hohnstraeter@gmx.de 
(c) 20I0 Authors; licensee IÖW and oekom verlag. This is an article distributed under the terms of the Creative Commons Attribution Non-Commercial No Derivates License (http://creativecommons.org/licenses/by-nc-nd/3.o/), which permits unrestricted use, distribution, and reproduction in any medium, provided the original work is properly cited. 